Mehmet Bulut*, Ahmet Erkliğ and Peyami Kanmaz

\title{
Vibration-damping characterization of the basalt/ epoxy composite laminates containing graphene nanopellets
}

https://doi.org/10.1515/secm-2017-0380

Received November 16, 2017; accepted June 11, 2018; previously published online September 6, 2018

\begin{abstract}
The present study investigates the influence of graphene nanopellets (GnPs) on the damping and vibration characteristics of fiber-reinforced basalt/epoxy composites for different weight contents of GnPs particles (0.1, 0.2 and $0.3 \mathrm{wt} \%)$. The variation of dynamic properties in terms of loss and storage modulus was explored by using the experimental modal analysis. The damping properties were determined by using logarithmic decrement method from the acceleration-time envelope curves. Results showed that the incorporation of GnPs at weight contents of $0.1 \%$ and $0.2 \%$ significantly affected the damping and vibration characteristics of the samples as a result of the interfacial strength between the GnPs particles-fiber-matrix interactions. The natural frequencies increased by $20.7 \%$ and $25 \%$ at GnPs contents of 0.1 and $0.2 \mathrm{wt} \%$, whereas the damping ratios increased by $28.5 \%$ and $57.1 \%$, respectively.
\end{abstract}

Keywords: composite materials; damping; graphene; nanocomposites; vibration.

\section{Introduction}

In recent years, basalt fiber has been extensively used in various engineering applications to meet the requirements of having high strength, durable, lightweight, high chemical, thermal and more economical properties [1-3]. As an inorganic material with harmless property, basalt fiber is produced from the molten rocks in the lava deposits through the extrusion process, and its fiber dimension is nearly 10-20 um [4, 5]. Recently, several researchers [6-9] have focused on the properties of basalt fibers, such as wide

*Corresponding author: Mehmet Bulut, Mechanical Engineering Department, Faculty of Engineering, Hakkari University, Hakkari 30000, Turkey, e-mail: mehmetbulut@hakkari.edu.tr. https://orcid.org/0000-0002-0705-6555

Ahmet Erkliğ: Mechanical Engineering Department, Faculty of Engineering, Gaziantep University, Gaziantep 27300, Turkey Peyami Kanmaz: Ege Ceramic Company, İzmir 335170, Turkey

Ә Open Access. (cc)BY $\odot 2019$ Walter de Gruyter GmbH, Berlin/Boston range of chemical resistance, mechanical strength and thermal resistance, while other researchers [10-12] have reported the fact that basalt fiber offers the higher mechanical properties, tensile strength and modulus compared with glass fibers. Many studies dealing with the mechanical, thermal and chemical components of basalt fiber are available in the literature. However, studies on the dynamic properties of basalt fiber are limited. As the application of basalt fibers in structural applications has increased, prediction and knowledge about the dynamic properties of structures made of basalt fibers are required as they are often subjected to external cyclic and impact loading, which significantly affect the stability of the system.

As basalt fiber is a novel fiber that has only become popular in recent years, only a few studies have been published on the damping and vibration properties of basalt fiber-reinforced composites. Yan et al. [13] investigated the dynamic stability of woven basalt/epoxy composite laminates under the quasi-static and high strain rate compression. They found that the phase and magnitude responses are highly sensitive to quasi-static and high strain rate loading conditions; the samples gradually acquired a stable condition while increasing strain rate. Bulut et al. [14] showed that damping properties of basalt fibers are lower than aramid fibers, and that the hybridization of basalt fibers with aramid fibers contributed to increasing damping properties while decreasing tensile strength. Recently, several researchers [15-17] reported that multiscale composites reinforced with micro- and nano-sized fillers within the polymer matrix composites exhibited higher thermal, electrical and mechanical properties than conventional composites. Furthermore, the mechanical and vibration characteristics of the composites could be controlled by the incorporation of nanoscale particles [18, 19]. The incorporation of nanotube fillers in the composites significantly increased the damping property with the advantage of interfacial friction between the nanotube particles in the matrix resin [20].

One study compared nano scale fillers with composites containing graphene nanopellet (GnPs) fillers and found that the latter are better functional and structural composite materials with improved mechanical, thermal and electrical properties and lower cost [21, 22]. One 
effective way to increase mechanical properties is to incorporate $\mathrm{GnPs}$ fillers in the epoxy resin because of the multifunctional property of the GnPs fillers, which can improve fracture energy by $115 \%$ at graphene loading of $0.124 \mathrm{wt} \%$ [23]. Although many studies on carbon nanotubes have been carried out and the factors that influence the vibration and damping properties of composite laminates [24-27], studies on GnPs fillers investigating the vibration properties of composites are limited [28, 29]. Moreover, no study has investigated the dynamic properties of basalt/ epoxy with GnPs interactions. Hence, this topic is should be investigated for sustaining safety and stability of the structural system.

The main novelty of this paper is that it explores the vibration and damping properties of basalt/epoxy composite laminates by incorporating the GnPs filler within the epoxy resin. The dynamic properties of basalt fiberreinforced composites were explored in terms of loss and storage modulus. We also studied the incorporation of $\mathrm{GnPs}$ with basalt fiber/epoxy composites for different GnPs particle weight contents only for the evaluation of fundamental frequency mode. Furthermore, the variation of damping and vibration properties was explained in relation to the interfacial interaction leading to increased load transfer between the GnPs particles and the basalt/epoxy matrix.

\section{Materials and procedures}

\subsection{Materials}

Basalt fibers with plain weaving architecture were supplied from Zhejiang GBF Basalt Fiber Co. Ltd. The basal fibers had an areal weight of $200 \mathrm{~g} / \mathrm{m}^{2}$ and thickness of $0.28( \pm 5 \%) \mathrm{mm}$. Chemical products like epoxy (MOMENTIVE-MGS L285) and hardener (MOMENTIVE
-MGS H285) were supplied by Dost Chemical Products Company, Istanbul, Turkey. Epoxy resin exhibits a density of $1.18 \mathrm{~g} / \mathrm{m}^{3}$, tensile strength of $70-80 \mathrm{MPa}$ and elastic modulus of 3.0-3.3 GPa. The volume fraction for basalt fibers was measured as $63 \%$. Graphene nanofiller was supplied from Grafnano Teknolojik Malzemeler Co. Ltd. (Kahramanmaraş, Turkey). The powder has a black and grey color and a purity of $99.5 \%$, bulk density of $\sim 0.05 \mathrm{~g} / \mathrm{cm}^{3}, 5 \mu \mathrm{m}$ diameter, thickness of $5-8 \mathrm{~nm}$ and a specific surface area of $150 \mathrm{~m}^{2} / \mathrm{g}$. The Raman spectra ID/ IG Ratio of 0.08 and XRD $2-\theta$ of $26^{\circ}$ peak.

\subsection{Manufacturing of composites}

The epoxy system was prepared by mixing the epoxy with hardener in the weight ratio of 100:40. Then, the GnPs filler was mixed and stirred in the epoxy at a certain amount. In order to reach a homogenous dispersion of GnPs particles, the stirring process was performed for about $20 \mathrm{~min}$. Then, the GnPs/epoxy mixture was applied by following the hand lay-up procedures for the impregnation of basalt fibers. The fabrics were wetted layer by layer to reach 10 layers of basalt laminates using a roller before the curing process. A hot mold press with flat molds was used for curing the impregnated nano-composites, subjecting the samples to $0.4 \mathrm{MPa}$ pressure for $1 \mathrm{~h}$ curing time with $80^{\circ} \mathrm{C}$ temperature. The nominal thickness of samples was measured as $1.9 \pm 0.2 \mathrm{~mm}$. Figure 1 illustrates the production process for $\mathrm{GnPs} /$ basalt nano composites and their tensile properties are provided in Table 1.

\subsection{Characterization and tensile properties}

The morphology of the GnPs/basalt fiber/epoxy was screened by using scanning electron microscopy SEM

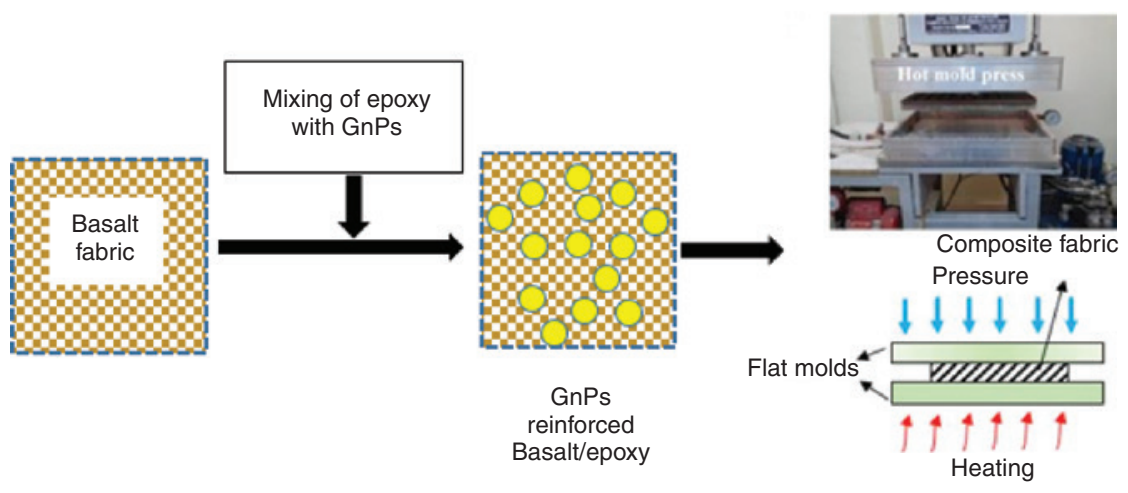

Figure 1: The production process for the composite samples. 
Table 1: The tensile test results of the produced test samples [30].

\begin{tabular}{lrrrr}
\hline GnPs content (wt\%) & Tensile strength (MPa) & Tensile modulus (GPa) & Tensile strain (mm/mm) & Energy at entire areas (J) \\
\hline Basalt/epoxy, control & 212 & 13.11 & 0.037 & 12.84 \\
0.1 & 240 & 15.92 & 0.042 & 16.78 \\
0.2 & 224 & 14.21 & 0.045 & 14.13 \\
0.3 & 223 & 13.34 & 0.042 & 15.09 \\
\hline
\end{tabular}

(JEOL JSM-6390 lv, Gaziantep University). The SEM images were taken over the edge surfaces of the test samples before the vibration tests. The vibration characteristics associated with GnPs dispersion in the epoxy resin were also explained by the SEM images.

\subsection{Vibration tests}

An accelerometer (PCB 352C03 ceramic shear ICP ${ }^{\circledR}$, PCB Piezotronics, Inc., Depew, NY, USA) for output signal, an impact hummer (PCB 086C03, PCB Piezotronics, Inc., Depew, NY, USA) for the excitation of the sample and a signal acquisition data card (NI 9234, National Instruments Corporation, Austin, TX, USA) with LABVIEW software were used. The manufactured test samples were excited by impact hammer to release the dynamic characteristics in terms of acceleration and frequency response. The free decaying curves of the samples were obtained with the excitation of the samples using the impact hammer. During the vibration tests, the frequency response curves of the samples were recorded as a function of amplitude and frequency $(\mathrm{Hz})$ by using the Fast Fourier Transforms (FFTs), which can be used to determine the natural frequencies and damping factors. The distribution of natural frequency values was measured within the constant frequency range from 0 to $500 \mathrm{~Hz}$. Figure 2 shows the experimental set-up to measure the vibration properties of the test samples, also indicating the location of the accelerometer and the test samples for the vibration tests.

The loss factor in every mode of vibration implies the proportion of energy dissipated by the structure, thus limiting the amplitudes of vibration resonance. The storage modulus represents the ability of energy storage in the material, thus denoting the elastic modulus of the material by means of dynamic modulus. The loss and storage modulus were calculated from log decrement method only for the first mode of natural frequencies.

A

A $\quad t=1.9 \pm 0.2 \mathrm{~mm}$
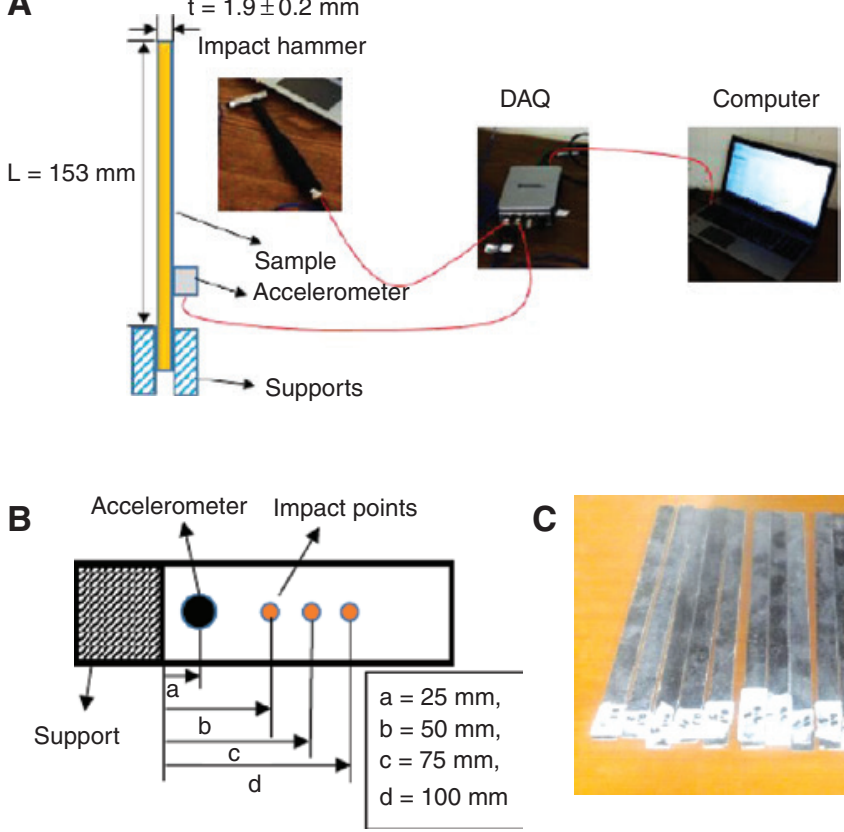

C

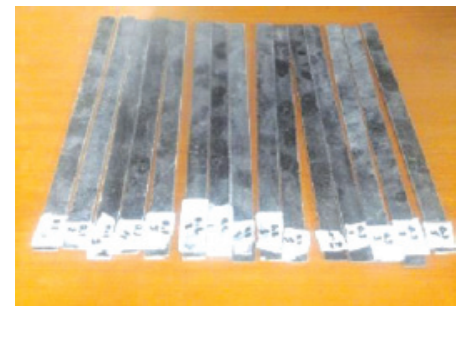

Figure 2: The vibration test mechanism. (A) Set-up for the vibration measurements, (B) the location of acceleration and impact points, (C) the test samples for the vibration measurement. 
One of the methods for the measurement of damping properties for an under-damped system is to perform the log decrement method. In this system, the vibration amplitude exponentially decays over time and the natural $\log$ of amplitudes of any two successive peaks is defined as logarithmic decrement or log decrement. The logarithmic decrement [31] can be evaluated by using Equation 1

$$
\delta=\frac{1}{n} \ln \frac{A_{0}}{A},
$$

where $\delta$ is the log decrement, $A_{0}$ is the maximum amplitude of first cycle and $A$ is the maximum amplitude of $n$th cycle. The damping ratio $(\xi)$ can be calculated from Equation 2 by substituting Equation 1 into Equation 2.

$$
\xi=\frac{1}{\sqrt{1+\left(\frac{2 \pi}{\delta}\right)^{2}}} .
$$

In addition, the storage modulus of the samples $\left(E^{\prime}\right)$ can be calculated from the Euler-Bernoulli beam theory as follows:

$$
\omega_{1}=\frac{1.875^{2}}{2 \pi L^{2}} \sqrt{\frac{E^{\prime} T}{\rho A}},
$$

where $\omega_{1}$ is the natural frequency of the first mode, $L$ is the free length of the beam, $\rho$ is the density of the beam,
$E^{\prime}$ is the storage modulus, $I$ is the moment of inertia for the given cross-section of beam and $A$ is the cross-section of beam. Similarly, the loss modulus $\left(E^{\prime \prime}\right)$ of the beam can be found using the storage modulus. The relationship between loss and storage modulus is given in Equation 4 below.

$$
E^{\prime \prime}=E^{\prime}(\omega) \operatorname{Tan}(\delta)=2 E^{\prime}(\omega) \xi(\omega)
$$

\section{Results and discussion}

\subsection{Tensile properties}

The tensile properties of the test samples are given in Table 1 and their SEM figures are illustrated in Figure 3 according to the GnPs content. As can be clearly seen, the composite samples with GnPs content of $0.1 \mathrm{wt} \%$ has shown the highest tensile strength and modulus compared with the other samples, indicating that the incorporation of the GnPs particles in the basalt/epoxy results in the improvement of tensile strength and modulus by $13 \%$ and $21 \%$, respectively. However, further increasing GnPs content after $0.1 \mathrm{wt} \%$ revealed the decreasing tensile strength and modulus with larger strains compared with the control samples. This can be explained by the agglomeration of particles, resulting in poor interfacial
A

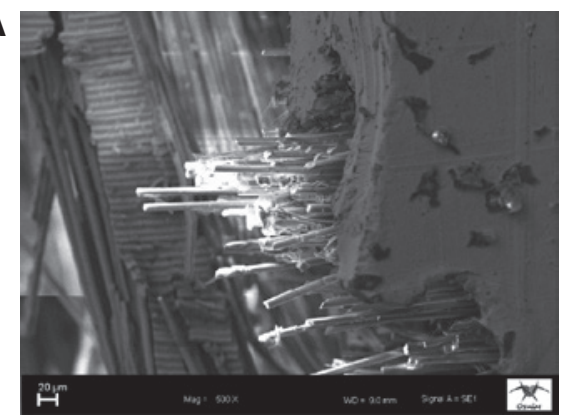

C

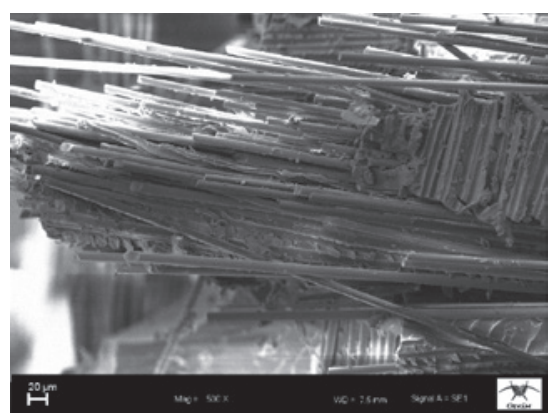

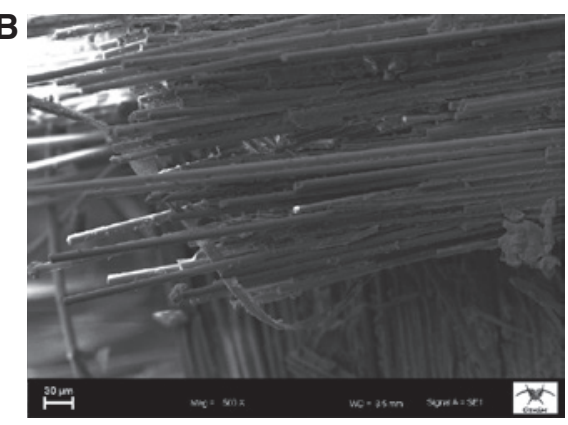

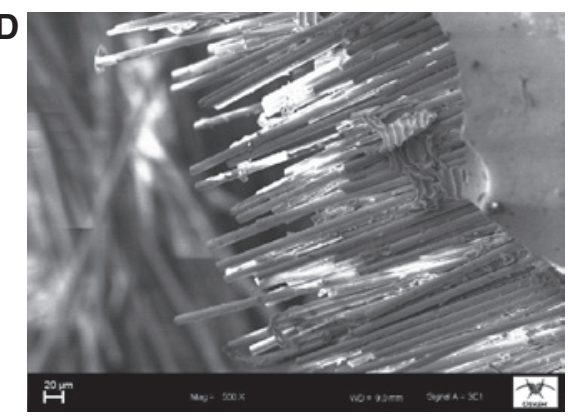

Figure 3: The SEM images of the composite samples. (A) Basalt/epoxy, control, (B) $0.1 \mathrm{wt} \%$, (C) $0.2 \mathrm{wt} \%$, (D) $0.3 \mathrm{wt} \%$. 
bonding between the particle-fiber-epoxy interactions. As can be seen in Figure 3C, the well distribution of the epoxy resin was observed with fine bonding at the interface of the epoxy and fibers. The epoxy-filled regions in the composites exhibit the homogenous distributed GnPs fillers in order to increase particle-fiber interactions for the improvement of load transfer. Due to the improved particle-fiber interactions at GnPs loading of $0.1 \mathrm{wt} \%$, it is possible to increase the mechanical properties while decreasing the deformation and strain, thus implying brittle characteristics. Further, the inclusion of GnPs particles resulted in decreased mechanical properties with increased deformation/strain properties, thus showing the enhancement of ductile characteristics in the material.

\subsection{Damping and vibration properties}

Figure 4 shows the response of the vibration curves of the samples with respect to the GnPs content. The frequency values are presented in Table 2 . As shown in the results, the incorporation of the GnPs filler in the epoxy resin slightly increased the natural frequency at the GnPs content of $0.1 \mathrm{wt} \%$ with improvements of $20.7 \%$ and $14.2 \%$ for the first and second mode of natural frequencies, respectively. These results suggest that high stiffness due to the high compatibility of the GnPs particles with basalt

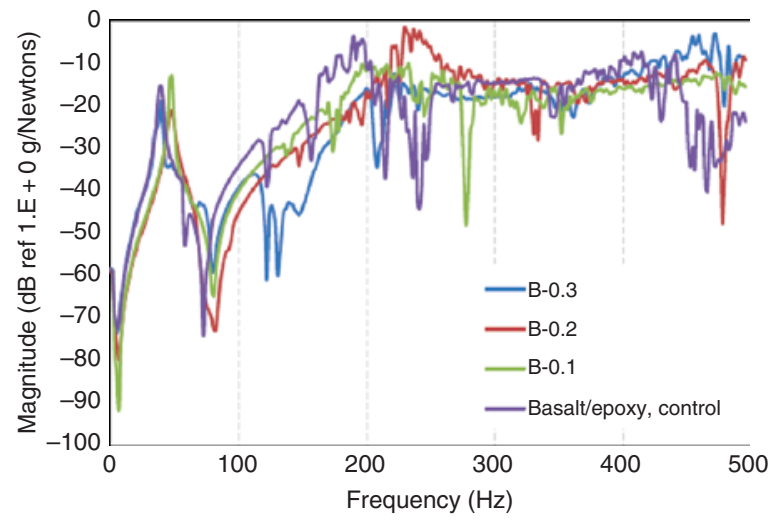

Figure 4: The frequency response curves of the samples.

Table 2: Vibration test results.

\begin{tabular}{lrrr}
\hline GnPs content (\% wt) & $\begin{array}{r}\text { First mode } \\
(\mathbf{H z})\end{array}$ & $\begin{array}{r}\text { Second mode } \\
(\mathbf{H z})\end{array}$ & Damping ratio \\
\hline Basalt/epoxy, control & $39.6 \pm 3$ & $189.9 \pm 6$ & $0.014 \pm 0.0012$ \\
0.1 & $47.8 \pm 2$ & $216.3 \pm 7$ & $0.018 \pm 0.0021$ \\
0.2 & $49.5 \pm 2$ & $232.8 \pm 4$ & $0.022 \pm 0.0013$ \\
0.3 & $39.8 \pm 3$ & $221.8 \pm 8$ & $0.019 \pm 0.0011$ \\
\hline
\end{tabular}

fiber/epoxy increased the natural frequency of the composite samples.

The modulus is directly to the natural frequency of the material. Thus, increasing the stiffness increases the natural frequency while decreasing the damping ratio. After the critical value of the stiffness at $0.1 \mathrm{wt} \%$ of the GnPs content, the decreasing trend was observed for stiffness and natural frequency while increasing damping property up to the GnPs content of $0.2 \mathrm{wt} \%$. After the GnPs content of $0.2 \mathrm{wt} \%$, both the damping and natural frequency properties were decreased when GnPs content was $0.3 \mathrm{wt} \%$. These findings suggest that agglomeration has been formed after the GnPs content of $0.1 \mathrm{wt} \%$ resulting in increased energy dissipation, with the faster rate leading to increased damping capacity [32, 33]. The low damping property is explained by the reduction in slippage effect between the particle and matrix, showing low energy absorption capacity for a composite system.

Figure 5 illustrates the variation of the log decrement curves according to the GnPs content for the comparison of damping properties. As can be seen, the inclusion of GnPs in the composites resulted in faster decaying to reach stable condition within the shorter time compared the control samples, thus implying the improvement of damping properties. Moreover, the damping ratio showed the highest value at the GnPs content of $0.2 \mathrm{wt} \%$, thus indicating that samples decay quickly and reach stability in a short time. Notably, both the natural frequency and damping properties had the highest values at the GnPs content of $0.2 \mathrm{wt} \%$, suggesting an increase in the stiffness and energy dissipation capacity of the samples. However, the further addition of GnPs particles after $0.2 \mathrm{wt} \%$ in the epoxy resin caused a reverse effect with the reduction of damping and natural frequency. This can be attributed to the agglomeration of the GnPs particles. Similarly, Farrash et al. [34] investigated the influence of CNT addition on the damping and vibration characteristics of the hybrid and non-hybrid composites, and they reported that the interfacial adhesion between the fibers and matrix had a major effect on the stiffness and damping properties of the composites. In addition this, incorporation of CNTs into the epoxy resin caused an increase in the fundamental frequency of both glass/epoxy and carbon/epoxy plates for the flexural mode.

\subsection{Dynamic mechanical properties}

The dynamic mechanical properties of test samples were characterized in terms of loss and storage modulus at the room temperature of $25^{\circ} \mathrm{C}$. The loss modulus refers to the damping characteristics of samples showing the ability of 

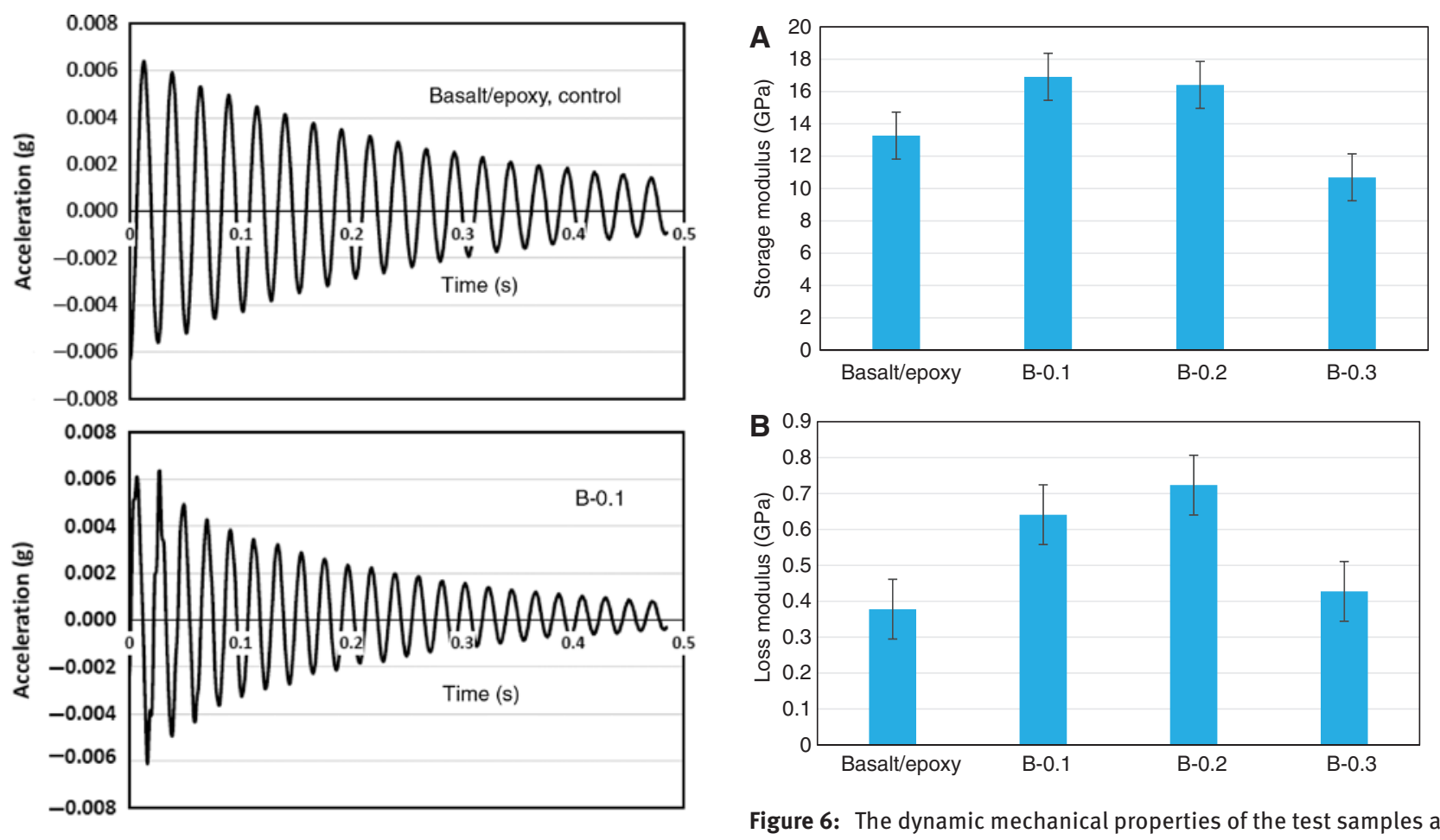

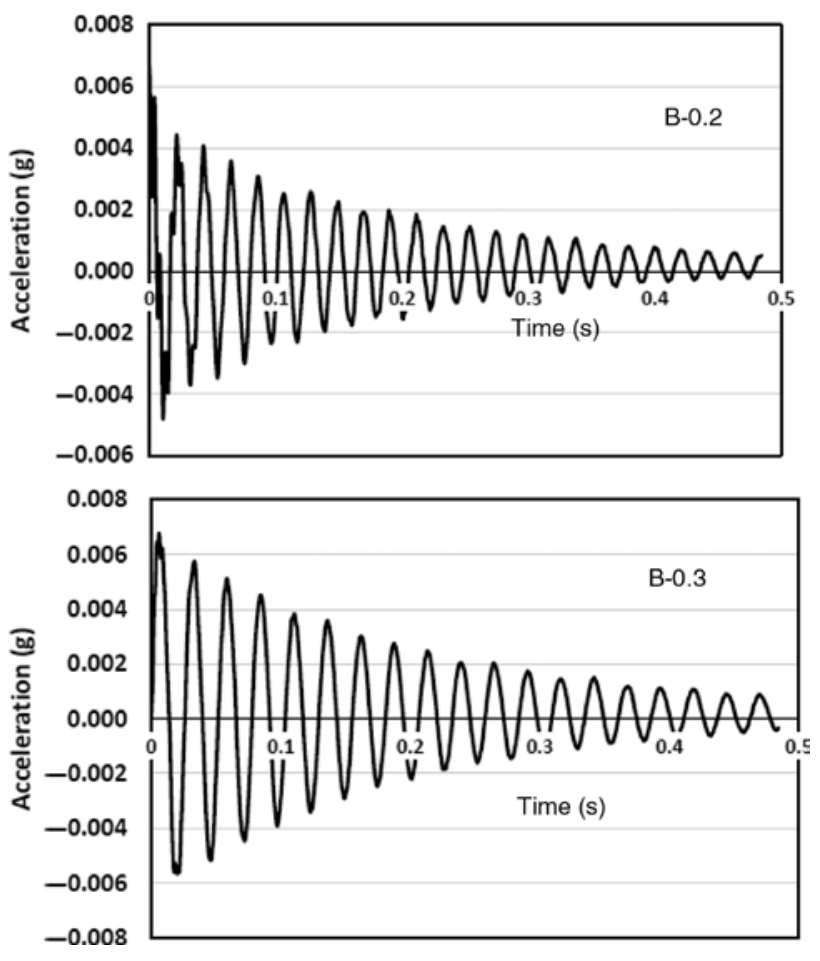

Figure 5: The free decay curves of the test samples with different GnPs loadings.

energy dissipation; hence, the controlling of loss modulus has been explored by the inclusion of the GnPs particles in the unmodified basalt/epoxy composites. It this way, it is possible to conclude that the interfacial bonding strength between the GnPs particle-fiber-epoxy interactions plays
Figure 6: The dynamic mechanical properties of the test samples at different GnPs loadings.

an important role in the dissipation of vibrational energy in the composite samples. Figure 6 shows the results of loss and storage values. Notably, the maximum improvement in loss modulus was recorded at the GnPs content of $0.2 \mathrm{wt} \%$, whereas the storage modulus showed the highest value at the GnPs content of $0.1 \mathrm{wt} \%$. Thus, the sample of B-0.1 exhibited the highest natural frequency as a result of elastic modulus as well as the further dissipation of vibration energy per cycle of damping than other samples. A decreasing trend in terms of storage modulus was observed as the GnPs content in the epoxy resin increased at the GnPs content of $0.1 \mathrm{wt} \%$. This was attributed to the decreased interfacial bonding of the GnPs particle-fiberepoxy interfaces due to particle agglomeration.

\section{Conclusion}

In this study, the effects of GnPs inclusion on the damping and vibration characterization of the basalt/epoxy composite laminates were investigated for different weight contents of GnPs particles. The results indicated that the incorporation of the GnPs filler in the basalt/epoxy composites significantly affected the damping and vibration responses. Specifically, the maximum improvement in the damping and natural frequency values were recorded as $36 \%$ and $25.6 \%$, respectively. The storage modulus and mechanical 
performance were at the highest value at the GnPs content of $0.1 \mathrm{wt} \%$, loss modulus was highest at a GnPs content of $0.2 \mathrm{wt} \%$, indicating lower energy dissipation capacity. Finally, it is possible to construct a basalt/epoxy composite system exhibiting high dynamic and mechanical performance while controlling a certain amount of GnPs particle in the epoxy resin. However, the excessive addition of GnPs particles in the composites resulted in decreased dynamic and mechanical performances. This can be attributed to the poor interfacial strength due to the agglomeration between the GnPs particles and fibers.

\section{References}

[1] Talib ARA, Ali A, Badie MA, Lah NAC, Golestaneh AF. Mater. Des. 2010, 31, 514-521.

[2] Park RC, Jang JS. Polym. Compos. 2001, 22, 80-89.

[3] Pavlovski D, Mislavsky B, Antonov A. Reinf. Plast. 2007, 37-39.

[4] Liu Q, Shaw MT, McDonnell AM, Parnas RS. Polym. Compos. 2006, 27, 41-48.

[5] Dhand V, Mittal G, Rhee KY, Park SJ, Hui D. Compos. B 2015, 73, 166-180.

[6] Botev M, Betchev H, Bikiaris D, Panayioyou C. J. Appl. Polym. Sci. 1999, 74, 523-531.

[7] Szabo JS, Czigany T. Polym. Test 2003, 22, 711-719.

[8] Ronkay F, Czigány T. Polym. Adv. Technol. 2006, 17, 830-834.

[9] Novitskii AG. Refract. Ind. Ceram. 2004, 45, 144-146.

[10] Fiore V, Scalici T, Di Bella G, Valenza A. Compos. B 2015, 74, 74-94.

[11] Sim J, Park C, Moon DY. Compos. B 2005, 36, 504-512.

[12] Artemenko SE. Fiber. Chem. 2003, 35, 226-229.

[13] Yan J, Gu B, Sun B. J. Reinf. Plast. Compos. 2013, 32, 137-144.
[14] Bulut M, Bozkurt ÖY, Erkliğ A. J. Polym. Eng. 2016, 36, 173-180.

[15] Bekyarova E, Thostenson ET, Yu A, Kim H, Gao J, Tang J. Langmuir 2007, 23, 3970-3974.

[16] Mohan TP, Kanny K. Adv. Compos. Mater. 2012, 21, 315-331.

[17] Kim MT, Rhee KY, Jung I, Park SJ, Hui D. Compos. B 2014, 63, 61-66.

[18] Suhr J, Koratkar N, Keblinski P, Ajayan P. Nat. Mater. 2005, 4, 134-137.

[19] Fu SY, Feng XQ, Lauke B, Mai YW. Compos. B 2008, 39, 933-961.

[20] Borbón F, Ambrosini D, Curadelli O. Compos. B 2014, 60, 106-110.

[21] Wu H, Drzal LT. Carbon 2012, 50, 1135-1145.

[22] Park OK, Kim SG, You NH, Ku BC, Hui D, Lee JH. Compos B 2014, 56, 365-371.

[23] Rafiee MA, Rafiee J, Wang Z, Song H, Yu Z-Z, Koratkar N. ACS Nano 2009, 3, 3884-3890.

[24] Bandow S, Chen G, Sumanasekera GU, Gupta R, Yudasaka M, lijima S, Eklund PC. Phys. Rev. B 2002, 66, 075416.

[25] Yoon J, Ru CQ, Mioduchowski A. Compos. Sci. Technol. 2003, 63, 1533-1542.

[26] Li C, Chou TW. Int. J. Solids Struct. 2003, 40, 2487-2499.

[27] He XQ, Kitipornchai S, Liew KM. J. Mech. Phys. Solids 2005, 53, 303-326.

[28] He XQ, Kitipornchai S, Liew KM. Nanotechnology 2005, 16, 2086-2091.

[29] Fan W, Li J, Chen L, Wang H, Guo D, Liu J. Polym. Compos. 2016, 37, 2871-2883.

[30] Bulut M. Compos. B Eng. 2017, 122, 71-78.

[31] Kabir A, Hoa SV. In: ICAF 2011 Structural Integrity: Influence of Efficiency and Green Imperatives, Komorowski J, Ed., Netherlands: Springer, 2011, pp. 155-165.

[32] Mohan TP, Ramesh KM, Velmurugan R. J. Mater. Sci. 2006, 41, 5915-5925.

[33] Rajini N, Winowlin Jappes JT, Rajakarunakaran S, Jeyaraj P. J. Reinf. Plast. Compos. 2012, 31, 1364-1376.

[34] Farrash SMH, Shariati M, Rezaeepazhand J. Compos. B 2017, 122, 1-8. 